A publications $\underset{G}{C}$ Rec. Nat. Prod. 13:2(2019) 176-181

records of natural products

\title{
Insecticidal Activity of Artemisia frigida Willd. Essential Oil and Its Constituents Against Three Stored Product Insects
}

\author{
Zhe Zhang $^{\oplus 1}$, Xue Pang ${ }^{\oplus 1}$, Shanshan Guo ${ }^{\oplus 1}$, Juqin Cao ${ }^{\oplus 1,2}$, Yang Wang ${ }^{\oplus 1}$, \\ Zhenyang Chen ${ }^{\oplus 1}$, Yixi Feng ${ }^{\oplus 1}$ Ning Lei $^{\oplus 3^{*}}$ and Shushan Du ${ }^{\oplus{ }^{*}}$ \\ ${ }^{1}$ Beijing Key Laboratory of Traditional Chinese Medicine Protection and Utilization; Faculty of \\ Geographical Science; Beijing Normal University, NO.19 Xinjiekouwai Street, Beijing 100875, P. R. \\ China \\ ${ }^{2}$ Medical Chemistry Department; School of Basic Medical Sciences; Ningxia Medical University, NO. \\ 1160 Shengli Street, Xingqing District, Yinchuan 750004, P. R. China \\ ${ }^{3}$ Department of Pharmacy; The General Hospital of the PLA Rocket Force, NO.16 Xinjiekouwai Street, \\ Beijing 100875, P. R. China
}

(Received June 09, 2018; Revised July 21, 2018; Accepted August 10, 2018)

\begin{abstract}
In this work, we investigated the chemical constituents of hydrodistillation essential oil from the aerial parts of Artemisia frigida Willd. All together 14 components were identified by GC-MS. Moreover, we tested the fumigant and contact activities of the essential oil and its five major individual compounds (terpinen-4-ol, verbenone, camphene, $\alpha$-terpineol and $\alpha$-terpinyl acetate) against Liposcelis bostrychophila, Lasioderma serricorne and Tribolium castaneum. In fumigant toxicity tests, $\alpha$-terpineol possessed the strongest activity (LC $\mathrm{L}_{50}$ $=3.27 \mathrm{mg} / \mathrm{L}$ air) against $L$. serricorne. Terpinen-4-ol exhibited the strongest activity $\left(\mathrm{LC}_{50}=0.08\right.$ and $3.74 \mathrm{mg} / \mathrm{L}$ air respectively) against $L$. bostrychophila and $T$. castaneum. As for contact toxicity, terpinen-4-ol and $\alpha$-terpinyl acetate exhibited fair toxicity against L. bostrychophila $\left(\mathrm{LD}_{50}=33.10\right.$ and $31.80 \mu \mathrm{g} / \mathrm{cm}^{2}$ respectively) and $L$. serricorne $\left(\mathrm{LD}_{50}=8.62\right.$ and $8.87 \mu \mathrm{g} /$ adult respectively), and camphene possessed the strongest activity $\left(\mathrm{LD}_{50}=\right.$ $5.13 \mu \mathrm{g} / \mathrm{adult})$ against $T$. castaneum. The results indicated that $A$. frigida essential oil and its individual compounds had the potential to be developed as natural fumigants and insecticides for control of these three stored-product insects.
\end{abstract}

Keywords: Artemisia frigida Willd.; essential oil; fumigant activity; contact activity; stored-product insects; GC; GC-MS. C 2018 ACG Publications. All rights reserved.

\section{Plant Source}

Fresh aerial parts of $A$. frigida were collected in August 2016 from Lanzhou City $\left(36^{\circ} 01^{\prime} \mathrm{N}\right.$ latitude and $103^{\circ} 45^{\prime}$ E longitude), Gansu Province, China. The species was identified by Dr. Liu, Q.R.

${ }^{*}$ Corresponding author: E-Mail: 1ilyzebra@163.com (N.Lei); dushushan@,bnu.edu.cn (S.Du)

The article was published by ACG Publications 
A voucher specimen (BNU-dushushan-20160808) was deposited at the Faculty of Geographical Science Beijing Normal University.

\section{Previous Studies}

Artemisia frigida Willd., a perennial semi-shrub distributed in the heavily grazed grasslands in Inner Mongolia Autonomous Region and the northern part of China, is a commonly used medicinal material in Mongolian traditional folk medicine to treat joint renal heat, abnormal menstruation, swelling, and sore carbuncle. A literature survey has shown that $A$. frigida extracts have contact activity and fumigant activity against $L$. bostrychophila and Sitophilus zeamais, however, the study only tested the bioactivities of essential oil from A. frigida and seldom mentioned its bioactive compounds [1]. To the best of our knowledge, the essential oil from A. frigida has never been previously reported to have fumigant and contact activities against $L$. serricorne and $T$. castaneum adults.

\section{Present Study}

Here we analyzed the chemical composition of the essential oil of A. frigida aerial parts and further investigated the fumigant and contact activities of its crude oil and its individual constituents against $L$. bostrychophila, $L$. serricorne and $T$. castaneum adults, and tried to find bioactive compounds.

Table 1. Chemical constituents identified from the essential oil of $A$. frigida aerial parts.

\begin{tabular}{|c|c|c|c|c|c|}
\hline NO. & RI exp. ${ }^{a}$ & RI lit. ${ }^{b}$ & Compounds & Peak area $(\%)$ & $\begin{array}{l}\text { Identified } \\
\text { Method }^{\mathrm{c}}\end{array}$ \\
\hline 1 & 941 & 951 & Camphene & 3.7 & MS; RI \\
\hline 2 & 997 & 996 & Yogomi alcohol & 6.5 & MS; RI \\
\hline 3 & 1032 & 1031 & 1,8-Cineole & 14.4 & MS; RI \\
\hline 4 & 1086 & 1080 & Artemisia alcohol & 3.1 & MS; RI \\
\hline 5 & 1117 & 1122 & $p$-2-Menthen-1-ol ${ }^{\mathrm{d}}$ & 1.1 & MS; RI \\
\hline 6 & 1124 & 1124 & 6-Camphenol & 3.6 & MS; RI \\
\hline 7 & 1145 & 1146 & Camphor & 45.0 & MS; RI \\
\hline 8 & 1156 & 1152 & Borneol & 3.5 & MS; RI \\
\hline 9 & 1177 & 1172 & Terpinen-4-ol & 5.1 & MS; RI \\
\hline 10 & 1188 & 1190 & $\alpha$-Terpineol & 2.6 & MS; RI \\
\hline 11 & 1206 & 1195 & Verbenone & 1.6 & MS; RI \\
\hline 12 & 1350 & 1367 & $\alpha$-Terpinyl acetate & 2.0 & MS; RI \\
\hline 13 & 1493 & 1491 & Bicyclogermacrene & 1.0 & MS; RI \\
\hline \multirow[t]{4}{*}{14} & 1506 & 1506 & $\beta$-Bisabolene & 1.9 & MS; RI \\
\hline & & & Monoterpene & 92.2 & \\
\hline & & & Sesquiterpene & 2.9 & \\
\hline & & & Total & 95.1 & \\
\hline
\end{tabular}

a RI exp., retention index as determined on HP-5MS column using the homologous series $\left(\mathrm{C}_{9}-\mathrm{C}_{17}\right)$ of $\mathrm{n}$ hydrocarbons. ${ }^{b}$ RI lit., retention index taken from literatures. ${ }^{c} \mathrm{MS}=$ based on comparison of mass spectra with those listed in the NIST 05 and Wiley 275 libraries and with published data. ${ }^{d}$ cis- or trans- $p$-2-Menthen-1-ol cannot be identified

Chemical components determination was carried out through GC-MS and GC-FID analysis. The essential oil was extracted from the aerial parts of $A$. frigida with the yield of $0.4 \%(\mathrm{v} / \mathrm{w})$ and the density of $0.938 \mathrm{~g} / \mathrm{mL}$. The GC-MS and GC-FID analysis results for the A. frigida essential oil were summarized in Table 1. Total 14 components were identified in A. frigida essential oil and the sum of these components was accounted for $95.1 \%$. The main components were camphor (45.0\%), 1,8-cineole 
(14.4\%), yogomi alcohol (6.5\%), terpinen-4-ol (5.1\%), camphene (3.7\%), 6-camphenol (3.6\%), borneol (3.5\%), artemisia alcohol (3.1\%), $\alpha$-terpineol $(2.6 \%), \alpha$-terpinyl acetate $(2.0 \%), \beta$-bisabolene $(1.9 \%)$ and verbenone (1.6\%). Among these compounds, we selected five major compounds (terpinen-4-ol, verbenone, camphene, $\alpha$-terpineol and $\alpha$-terpinyl acetate) to test the bioactivities against three stored product insects along with $A$. frigida essential oil.

These results were different to those reported in the published literatures. For example, A. frigida essential oil collected from Inner Mongolia province mainly contained cis- $\rho$-menth-2-en-1-ol $(20.8 \%)$, 1,8-cineole (12.0\%), borneol (10.2\%), lavandulol (9.3\%) and camphor (6.9\%) [1]. The main components of $A$. frigida essential oil collected from Central Alberta Prairies, Canada, were camphor (20.6\%), 1,8-cineole (25.1\%), chrysanthenone (7.4\%), borneol (8.1\%) and camphene (4.1\%) [2]. And the essential oil of $A$. frigida collected on the catchment area of Lake Baikal showed that samples from different populations all have these components: 1,8-cineole (6.6-23.4\%), camphor (3.6-35.9\%), borneol (6.1-7.0\%), terpinen-4-ol (4.2-14.1\%), bornyl acetate (1.1-6.0\%) and germacrene D (1.4-5.0\%) [3]. It was believed that the variety of harvest time, regional habitat conditions and growing years might result in an obvious difference in the composition of the volatile oil. On the other hand, those studies also found some common compounds, such as camphor and 1,8-cineole, the finding was corresponded with previous research that bornane derivatives and 1,8-cineole were major characteristic components of many essential oils of Artemisia species [4].

Table 2. Fumigant toxicity of $A$. frigida essential oil and individual compounds against $L$. bostrychophila (LB), L. serricorne (LS), and T. castaneum (TC) adults

\begin{tabular}{|c|c|c|c|c|c|c|}
\hline Insects & Samples & $\begin{array}{c}\mathrm{LC}_{50}{ }^{\mathrm{a}} \\
\text { (mg/L air) }\end{array}$ & $\begin{array}{c}95 \% \text { FL } \\
\text { (mg/L air) }\end{array}$ & Slope \pm SE & Chi-square & P-value \\
\hline \multirow{7}{*}{ LB } & The oil & 0.52 & $0.46-0.58$ & $1.42 \pm 0.19$ & 10.02 & 0.931 \\
\hline & Terpinen-4-ol & 0.08 & $0.07-0.08$ & $4.68 \pm 0.81$ & 15.76 & 0.865 \\
\hline & Verbenone & 0.14 & $0.13-0.15$ & $14.79 \pm 1.51$ & 14.76 & 0.903 \\
\hline & Camphene & - & - & - & - & - \\
\hline & $\alpha$-Terpineol & 0.58 & $0.52-0.65$ & $4.66 \pm 0.55$ & 10.40 & 0.918 \\
\hline & $\begin{array}{l}\alpha \text {-Terpinyl } \\
\text { acetate }\end{array}$ & 0.39 & $0.37-0.42$ & $2.96 \pm 0.41$ & 13.98 & 0.730 \\
\hline & Dichlorvos ${ }^{\mathrm{b}}$ & $1.35 \times 10^{-3}$ & $(1.25-1.47) \times 10^{-3}$ & $6.90 \pm 0.60$ & 10.40 & - \\
\hline \multirow{7}{*}{ LS } & The oil & 4.53 & $3.91-5.12$ & $4.05 \pm 0.54$ & 18.15 & 0.446 \\
\hline & Terpinen-4-ol ${ }^{\mathrm{c}}$ & 6.90 & $6.04-7.84$ & - & 19.84 & - \\
\hline & Verbenone & - & - & - & - & - \\
\hline & Camphene & 8.78 & $5.75-11.15$ & $2.47 \pm 0.45$ & 10.53 & 0.987 \\
\hline & $\alpha$-Terpineol ${ }^{c}$ & 3.27 & $3.17-3.38$ & $12.12 \pm 1.51$ & 19.09 & 0.986 \\
\hline & $\begin{array}{l}\alpha \text {-Terpinyl } \\
\text { acetate }\end{array}$ & - & - & - & - & - \\
\hline & Phosphine $^{\mathrm{d}}$ & $9.23 \times 10^{-3}$ & $(7.13-11.37) \times 10^{-3}$ & $2.10 \pm 0.30$ & 12.00 & - \\
\hline \multirow{7}{*}{$\mathrm{TC}$} & The oil & 6.79 & $6.08-7.58$ & $4.72 \pm 0.57$ & 7.41 & 0.986 \\
\hline & Terpinen-4-ol ${ }^{\mathrm{e}}$ & 3.74 & $3.30-4.26$ & - & 12.44 & - \\
\hline & Verbenone & 7.09 & $6.00-10.05$ & $3.54 \pm 0.53$ & 6.97 & 0.904 \\
\hline & Camphene & 4.10 & $3.55-4.68$ & $3.51 \pm 0.47$ & 14.02 & 0.698 \\
\hline & $\alpha$-Terpineol & - & - & - & - & - \\
\hline & $\begin{array}{l}\alpha \text {-Terpinyl } \\
\text { acetate }\end{array}$ & - & - & - & - & - \\
\hline & $\mathrm{MeBr}^{\mathrm{f}}$ & 1.75 & - & - & - & - \\
\hline
\end{tabular}

a $50 \%$ of lethal concentration. ${ }^{b}$ Date from Zhao et al [7]. ${ }^{\mathrm{c}}$ Date from Zhang et al [8]. ${ }^{\mathrm{d}}$ Date from You et al [9]. ${ }^{\mathrm{e}}$ Date from Zhang et al [10]. ${ }^{\mathrm{f}}$ Date from Liu and Ho [11]. 
We have tested the bioactivities of $A$. frigida essential oil and five major individual compounds (terpinen-4-ol, verbenone, camphene, $\alpha$-terpineol and $\alpha$-terpinyl acetate). The results of fumigant assays for the oils are presented in Table 2. In fumigant toxicity tests, the essential oil extracted from the aerial parts of $A$. frigida showed pronounced toxicity against $L$. bostrychophila, $L$. serricorne and $T$. castaneum with $\mathrm{LC}_{50}$ values of $0.52,4.53$ and $6.79 \mathrm{mg} / \mathrm{L}$ air respectively. When it came to $L$. bostrychophila adults, terpinen-4-ol exhibited the strongest fumigant toxicity of $\mathrm{LC}_{50}=0.80 \mathrm{mg} / \mathrm{L}$ air. Verbenone was 1.7 times less toxic than terpinen-4-ol and $\alpha$-terpinyl acetate was 4.8 times less toxic than terpinen-4-ol, however, these two compounds were not so much effective against L. serricorne in our fumigant toxicity measure range and their $\mathrm{LC}_{50}$ values could not be calculated $\left(\mathrm{LC}_{50}>50.0 \mathrm{mg} / \mathrm{L}\right.$ air). Although $\alpha$-terpineol has weakest fumigant against $L$. bostrychophila, it has the strongest activity against $L$. serricorne $\left(\mathrm{LC}_{50}=3.27 \mathrm{mg} / \mathrm{L}\right.$ air). Compared with the positive control (dichlorvos, $\mathrm{LC}_{50}=$ $1.35 \times 10^{-3} \mathrm{mg} / \mathrm{L}$ air; phosphine, $\mathrm{LC}_{50}=9.23 \times 10^{-3} \mathrm{mg} / \mathrm{L}$ air), the fumigant toxicities of $A$. frigida essential oil and its compounds against L. bostrychophila and L. serricorne were weaker. However, compared with the fumigant activity of the other oils reported in the literature which were tested using a similar bioassay, the essential oil obtained in the present study exhibited the same or stronger fumigant toxicity against $L$. bostrychophila and $L$. serricorne, e.g. the $A$. frigida essential oil possessed the same level of fumigant toxicity to L. bostrychophila as that of Ajania fruticulosa essential oil $\left(\mathrm{LC}_{50}=0.65\right.$ $\mathrm{mg} / \mathrm{L}$ air) and the same level of fumigant toxicity to L. serricorne as that of Artemisia mongolica essential oil ( $\mathrm{LC}_{50}=6.08 \mathrm{mg} / \mathrm{L}$ air) $[5,6]$. When it came to $T$. castaneum adults, the essential oil and its components exhibited fair toxicity and they had fumigant activity from $\mathrm{LC}_{50}=3.74 \mathrm{mg} / \mathrm{L}$ air to 7.09 $\mathrm{mg} / \mathrm{L}$ air. Although terpinen-4-ol also exhibited the strongest fumigant toxicity $\left(\mathrm{LC}_{50}=3.74 \mathrm{mg} / \mathrm{L}\right.$ air $)$ which was just 2.14 times less toxic than the positive control ( $\mathrm{MeBr}, \mathrm{LC}_{50}=1.75 \mathrm{mg} / \mathrm{L}$ air), it was not obviously different from camphene $\left(\mathrm{LC}_{50}=4.10 \mathrm{mg} / \mathrm{L}\right.$ air $)$ since their $95 \%$ confidence limit values overlap with each other.

The results of contact assays for the essential oil and its compounds against $L$. bostrychophila, $L$. serricorne and $T$. castaneum adults are presented in Table 3. Compared to the fumigant toxicity, the contact toxicity was more remarkable against $L$. bostrychophila and $L$. serricorne. Except for camphene and $\alpha$-terpineol with negligible toxic effects $\left(\mathrm{LC}_{50}\right.$ could not be calculated under the tested concentrations in the preliminary test) against L. bostrychophila and T. castaneum respectively, all of the other compounds analyzed showed toxic effects against these three stored product pests. The crude oil was always less contact toxic than its compounds against these three stored product pests. When it came to L. bostrychophila adults, terpinen-4-ol and $\alpha$-terpinyl acetate showed similar contact activity $\left(\mathrm{LD}_{50}=33.10\right.$ and $\left.31.80 \mu \mathrm{g} / \mathrm{cm}^{2}\right)$ since their $95 \%$ confidence limit values overlap with each other and they were just about 1.7 times less toxic than the positive control (pyrethrins, $\mathrm{LD}_{50}=18.72 \mu \mathrm{g} / \mathrm{cm}^{2}$ ). As for $L$. serricorne, terpinen-4-ol and $\alpha$-terpinyl acetate exhibited fair contact activities of $\mathrm{LD}_{50}=8.62$ $\mu \mathrm{g} /$ adult and $8.87 \mu \mathrm{g} /$ adult respectively. Except for $\alpha$-terpineol, other four major individual compounds had activities from $\mathrm{LD}_{50}=5.13$ to $9.60 \mu \mathrm{g} /$ adult against $T$. castaneum adults and camphene exhibited the strongest contact toxicity $\left(\mathrm{LD}_{50}=5.13 \mu \mathrm{g} / \mathrm{adult}\right)$.

By the structural analysis, terpinen-4-ol, $\alpha$-terpineol and $\alpha$-terpinyl acetate had the similar structures, however, the insecticidal activities of them are quite different. In fumigant tests, $\alpha$-terpinyl acetate possessed weaker activity than terpinen-4-ol and $\alpha$-terpineol which might due to its ester fragment. Moreover, in our previous work, oxygen-containing groups had been found to enhance the insecticide activities of essential oils [15], e.g. camphor, which has a similar structure to camphene, was reported to possess a fumigant activity of $\mathrm{LC}_{50}=0.43 \mathrm{mg} / \mathrm{L}$ air against $L$. bostrychophila by Liang et al [5]. Comparing camphor to camphene, the former had stronger fumigant toxicity and it had a ketone group. In our tests, terpinen-4-ol, verbenone and $\alpha$-terpinyl acetate all had oxygen-containing groups and they have been certified to possess fair contact activity. 
Table 3. Contact toxicity of $A$. frigida essential oil and individual compounds against $L$. bostrychophila (LB), $L$. serricorne (LS) and T. castaneum (TC) adults

\begin{tabular}{|c|c|c|c|c|c|c|}
\hline Insects & Samples & $\begin{array}{c}\mathrm{LD}_{50}\left(\mathrm{ug} / \mathrm{cm}^{2} \text { for LB; }\right. \\
\mu \mathrm{g} / \text { adult for TC and LS) }\end{array}$ & $95 \% \mathrm{FL}$ & Slope \pm SE & Chi-square & $P$-value \\
\hline \multirow{7}{*}{ LB } & The oil & 78.18 & $74.52-81.98$ & $7.24 \pm 0.90$ & 15.55 & 0.624 \\
\hline & Terpinen-4-ol & 33.10 & $30.59-35.74$ & $6.61 \pm 0.71$ & 8.01 & 0.928 \\
\hline & Verbenone & 35.15 & $33.79-36.51$ & $18.99 \pm 2.00$ & 16.23 & 0.845 \\
\hline & Camphene & - & - & - & - & - \\
\hline & $\alpha$-Terpineol & 37.76 & $33.60-41.17$ & $7.32 \pm 0.99$ & 4.25 & 0.994 \\
\hline & $\alpha$-Terpinyl acetate & 31.80 & $30.13-33.41$ & $12.82 \pm 1.78$ & 12.10 & 0.520 \\
\hline & Pyrethrins $^{\mathrm{a}}$ & 18.72 & $17.60-19.92$ & $2.98 \pm 0.40$ & 10.56 & 0.987 \\
\hline \multirow{7}{*}{ LS } & The oil & 16.84 & $14.26-19.50$ & $3.70 \pm 0.56$ & 14.42 & 0.971 \\
\hline & Terpinen-4-ol ${ }^{\mathrm{b}}$ & 8.62 & $7.38-9.85$ & - & 12.65 & - \\
\hline & Verbenone & 12.10 & $10.93-13.33$ & $4.61 \pm 0.50$ & 19.77 & 0.656 \\
\hline & Camphene & 17.73 & $12.24-21.94$ & $17.87 \pm 0.35$ & 18.80 & 0.526 \\
\hline & $\alpha$-Terpineol ${ }^{\mathrm{b}}$ & 11.99 & $10.42-13.42$ & $3.12 \pm 0.43$ & 18.96 & 0.624 \\
\hline & $\alpha$-Terpinyl acetate & 8.87 & $7.61-10.25$ & $3.10 \pm 045$ & 13.75 & 0.745 \\
\hline & Pyrethrins & 0.24 & $0.16-0.35$ & $1.31 \pm 0.2$ & 17.36 & - \\
\hline \multirow{7}{*}{$\mathrm{TC}$} & The oil & 25.22 & $21.39-29.17$ & $3.70 \pm 0.56$ & 14.42 & 0.345 \\
\hline & Terpinen-4-ol ${ }^{\mathrm{c}}$ & 7.65 & $6.75-8.55$ & $2.21 \pm 0.33$ & 18.77 & 0.715 \\
\hline & Verbenone & 9.60 & $8.13-11.17$ & $3.54 \pm 0.53$ & 6.97 & 0.904 \\
\hline & Camphene & 5.13 & $4.32-5.91$ & $2.76 \pm 0.38$ & 16.82 & 0.496 \\
\hline & $\alpha$-Terpineol & - & - & - & - & - \\
\hline & $\alpha$-Terpinyl acetate & 9.28 & $6.78-11.35$ & $2.37 \pm 0.43$ & 15.71 & 0.613 \\
\hline & Pyrethrins ${ }^{\mathrm{d}}$ & 0.26 & $0.22-0.30$ & $3.34 \pm 0.32$ & 13.11 & 0.950 \\
\hline
\end{tabular}

${ }^{a}$ Date from Liu et al [12]. ${ }^{b}$ Date from Zhang et al [8]. ${ }^{c}$ Date from Wang et al [13]. ${ }^{d}$ Date from Guo et al [14].

It was reported that essential oils from plants and their constituents can be useful alternatives to conventional insecticides and fumigants due to no residues dangerous of stored food treated with such products for human health and environmentally safe [16-18]. This work indicates that the A. frigida essential oil and its individual constituents have potential to be developed into natural insecticides for the control of insects in stored products. However, further studies also should be focus on evaluating the efficacy, safety and cost of the essential oil and its compounds in a wide range of practical storage applications.

\section{Acknowledgments}

This project was supported by The National Key R\&D Program of China (2016YFC0500805).

\section{Supporting Information}

Supporting information accompanies this paper on http://www.acgpubs.org/journal/recordsof-natural-products

\section{ORCID}

Zhe Zhang: $0000-0002-6956-3456$

Xue Pang: 0000-0002-5544-1968

Shanshan Guo: 0000-0002-2981-939X

Juqin Cao: 0000-0001-6095-236X

Yang Wang: 0000-0003-1364-5142

Zhenyang Chen: 0000-0002-5130-7331

Yixi Feng: 0000-0002-3376-4512

Ning Lei: $\underline{0000-0002-4920-2127}$ 
Shushan Du: $\underline{0000-0003-0037-2480}$

\section{References}

[1] X. C. Liu, Y. Li, T. Wang, Q. Wang and Z. L. Liu (2014). Chemical composition and insecticidal activity of essential oil of Artemisia frigida Willd (Compositae) against two grain storage insects, Trop. J. Pharm. Res. 13, 587-592.

[2] D. Lopes-Lutz, D. S. Alviano, C. S. Alviano and P. P. Kolodziejczyk (2008). Screening of chemical composition, antimicrobial and antioxidant activities of Artemisia essential oils, Phytochemistry 69, 1732-1738.

[3] N. V. Bodoev, S. V. Bazarova, L. M. Pokrovsky, B. B. Namzalov and A. V. Tkachev (2000). Chemical composition of Artemisia frigida Willd. essential oil from Russia, Khimiya Rastitel'nogo Syr'ya 3, 41-44.

[4] S. Kordali, R. Kotan, A. Mavi, A. Cakir, A. Ala and A. Yildirim (2005). Determination of the chemical composition and antioxidant activity of the essential oil of Artemisia dracunculus and of the antifungal and antibacterial activities of Turkish Artemisia absinthium, A. dracunculus, Artemisia santonicum, and Artemisia spicigera essential oils, J. Agr. Food Chem. 53, 9452-9458.

[5] J. Y. Liang, S. S. Guo, C. X. You, W. J. Zhang, C. F. Wang, Z. F. Geng, Z. W. Deng, S. S. Du and J. Zhang (2016). Chemical constituents and insecticidal activities of Ajania fruticulosa essential oil, Chem. Biodiversity 13, 1053-1057.

[6] C. X. You, S. S. Guo, W. J. Zhang, K. Yang, Z. F. Geng, S. S. Du, C. F. Wang and Z. W. Deng (2015). Identification of repellent and insecticidal constituents from Artemisia mongolica essential oil against Lasioderma serricorne, J. Chem. 3, 1-7.

[7] M. P. Zhao, X. C. Liu, D. W. Lai, L. G. Zhou and Z. L. Liu (2016). Analysis of the essential oil of Elsholtzia ciliate aerial parts and its insecticidal activities against Liposcelis bostrychophila, Helv. Chim. Acta. 99, 90-94.

[8] W. J. Zhang, S. S. Guo, C. X. You, Z. F. Geng, J. Y. Liang, Z. W. Deng, C. F. Wang, S. S. Du and Y. Y. Wang (2016). Chemical composition of essential oils from Zanthoxylum bungeanum Maxim. and their bioactivities against Lasioderma serricorne, J. Oleo Sci. 65, 871-879.

[9] C. X. You, Y. Wang, W. J. Zhang, K. Yang, Y. Wu, Z. F. Geng, H. P. Chen, H. Y. Jiang, S. S. Du, Z. W. Deng and Z. L. Liu (2014). Chemical constituents and biological activities of the Purple Perilla essential oil against Lasioderma serricorne, Ind. Crops Prod. 61, 331-337.

[10] W. J. Zhang, K. Yang, C. X. You, Y. Wang, C. F. Wang, Y. Wu, Z. F. Geng, Y. Su, S. S. Du and Z. W. Deng (2015). Bioactivity of essential oil from Artemisia stolonifera (Maxim.) Komar. and its main compounds against two stored-product insects, J. Oleo Sci. 64, 299-307.

[11] Z. L. Liu and S. H. Ho (1999). Bioactivity of the essential oil extracted from Evodiarutaecarpa Hook f. et Thomas against the grain storage insects, Sitophiluszeamais Motsch. and Tribolium castaneum (Herbst), J. Stored Prod. Res. 35, 317-328.

[12] X. C. Liu, L. G. Zhou, Z. L. Liu and S. S. Du (2013). Identification of insecticidal constituents of the essential oil of Acorus calamus rhizomes against Liposcelis bostrychophila Badonnel, Molecules 18, 5684-5696.

[13] Y. Wang, C. X. You, C. F. Wang, K. Yang, R. Chen, W. J. Zhang, S. S. Du, Z. F. Geng and Z. W. Deng (2013). Chemical constituents and insecticidal activities of the essential oil from Amomum tsaoko against two stored-product insects, J. Oleo Sci. 63, 1019-1026.

[14] S. S. Guo, W. J. Zhang, J. Y. Liang, C. X. You, Z. F. Geng, C. F. Wang and S. S. Du (2016). Contact and repellent activities of the essential oil from Juniperus formosana against two stored product insects, Molecules 21, 504.

[15] Z. Zhang, S. S. Guo, W. J. Zhang, Z. F. Geng, J. Y. Liang, S. S. Du, C. F. Wang and Z. W. Deng (2017). Essential oil and polyacetylenes from Artemisia ordosica and their bioactivities against Tribolium castaneum Herbst (Coleoptera: Tenebrionidae.), Ind. Crops Prod. 100, 132-137.

[16] S. Perrucci, G. Macchioni, P. L. Gioni, G. Flamini and I. Morelli (1995). Structure toxicity relationship of some natural monoterpenes as acaricides against Psoroptes cuniculi, J. Nat. Prod. 58, 1261-1264.

[17] R. Pavela (2014). Insecticidal properties of Pimpinella anisum essential oils against the Culex quinq fasciatus and the non-target organism Daphnia magna, J. Asia Pac. Entomol. 17, 287-293.

[18] R. Pavela and M. Govindarajan (2016). The essential oil from Zanthoxylum monophyllum a potential mosquito larvicide with low toxicity to the non-target fish Gambusia affinis, J. Pest Sci. 90, 369-378.

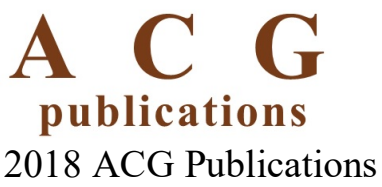

